\title{
PREVALENCE OF MALIGNANCY IN ORAL WHITE LESIONS
}

\author{
Celine Machiyanickal Issac ${ }^{1}$, Neethu Jacob², Sadeep Melathil Sadandan ${ }^{3}$, Shobhanakumari Kunjumani4, Mary Vineetha ${ }^{5}$
}

${ }^{1}$ Assistant Professor, Department of Dermatology and Venereology, Government Medical College, Kottayam.

${ }^{2}$ Dermatologist, Department of Dermatology and Venereology, Holy Ghost Hospital, Muttuchira.

${ }^{3}$ Professor, Department of Dermatology and Venereology, Government Medical College, Kottayam.

4 Professor, Department of Dermatology and Venereology, Government Medical College, Kottayam.

${ }_{5}^{5}$ Assistant Professor, Department of Dermatology and Venereology, Government Medical College, Kottayam.

ABSTRACT

\section{BACKGROUND}

White lesions in the oral cavity may be benign, pre-malignant or malignant. In India, oral cancer ranks first among all cancers in males and third among females. The five-year survival in oral cancer is directly related to the stage at diagnosis.

The aim of this study was to investigate the various clinical and histological patterns of keratotic white lesions of oral mucosa and early detection of malignant changes to avert life threatening complications.

\section{MATERIALS AND METHODS}

95 patients with keratotic white lesions in the oral cavity who attended outpatient wing of Department of Dermatology and Oral medicine between April 2012 to October 2013 in our tertiary care centre were studied.

\section{RESULTS}

Out of 61 clinically diagnosed lichen planus 6.5\% showed histological disparity. $20.6 \%$ showed malignant change among 29 leukoplakia cases and site of involvement of these patients was over dorsum and lateral aspect of tongue and floor of mouth. Clinically diagnosed oral submucous fibrosis did not showed any evidence of dysplasia. No clinicohistopathologic correlation was observed in DLE lesions. Habit of smoking, alcoholism, betel chewing and pan masala use were higher in those patients with malignancy.

Limitations- Lack of follow-up of cases.

\section{CONCLUSION}

Persistence of suspicious lesion beyond 2-6 weeks, warrants need for oral biopsy. Failure to recognize a suspicious white lesion may result in a stage where treatment is not feasible.

\section{KEYWORDS}

Oral White Lesion, Leukoplakia, Malignancy in Oral Lesions.

HOW TO CITE THIS ARTICLE: Issac CM, Jacob N, Sadandan SM, et al. Prevalence of malignancy in oral white lesions. J. Evolution Med. Dent. Sci. 2017;6(9):699-703, DOI: 10.14260/Jemds/2017/151

\section{BACKGROUND}

White lesions may be due to local, congenital, inflammatory, infective, immunological, preneoplastic or neoplastic causes. ${ }^{1}$ Lesions appear white in the oral cavity because the abnormal keratin can reflect the spectrum of light evenly and also the constant bathing of the hyperkeratotic tissue in saliva, analogous to the appearance of palms and soles when immersed in water for long periods. ${ }^{2}$ It is a very common practice to classify majority of white lesions as 'Leukoplakia'. The WHO working group redefined leukoplakia in 2007 as "the term leukoplakia should be used to recognize white plaques of questionable risk having excluded (Other) known diseases or disorders that carry no increased risk for cancer". 3 Oral cancer ranks eighth among all the cancers worldwide. In India, it ranks first among all cancers in males and third among cancers in females. ${ }^{4}$ The five-year survival in

Financial or Other, Competing Interest: None.

Submission 22-12-2016, Peer Review 15-01-2017,

Acceptance 21-01-2017, Published 30-01-2017.

Corresponding Author:

Dr. Celine Machiyanickal Issac,

Assistant Professor,

Department of Dermatology and Venereology,

Government Medical College, Kottayam, Kerala.

E-mail: dr.miceline@gmail.com

DOI: $10.14260 /$ jemds $/ 2017 / 151$ oral cancer is directly related to the stage at diagnosis, and so prevention and early detection efforts have the potential not only for decreasing the incidence, but also for improving the survival of those who develop the disease. ${ }^{5}$ Smoking, alcohol consumption and chewing tobacco products which are common habits in India have been positively associated with oral lesions including malignancy. In South East Asia and especially in India, the medical community has sent out an alert for an epidemic of oral cancer due to the use of betel quid substitutes-gutkha and pan masala. ${ }^{6}$

The present study is aimed to evaluate the various clinical and pathological features of keratotic white lesions of oral mucosa with special emphasis on premalignant lesions. Accurate identification of a premalignant process or malignancy in the early stages yields an excellent prognosis, for complete recovery, without disfiguration or loss of function.

\section{MATERIALS AND METHODS}

After obtaining ethical committee clearance the study was conducted in our tertiary care centre from April 2012October 2013. All patients with oral white keratotic/nonscrapable lesions were included in the study. Patients with age less than 10 years, pregnant women and patients not willing for oral biopsy were excluded. 
After obtaining a well-informed written consent, data was entered in a pre-set format. Detailed clinical history including presenting complaints, duration of disease, personal habits, past history, drug history and family history were obtained. Detailed examination of oral cavity including regional nodes, other mucosae, skin and systems were done. Clinical diagnosis was made based on history and clinical findings.

Complete blood count, urine examination, RBS, VDRL test, ELISA for HIV, HBsAg, HCV, scraping for candida in $10 \% \mathrm{KOH}$ were done in all cases and findings were recorded. Patients were explained about the disease and need for biopsy. A written consent was obtained for biopsy.

Data was entered in Excel and statistical analysis performed using Microsoft Excel and Statistical Package for Social Science (SPSS) for Windows.

\section{RESULTS}

Ninety-five patients were included in the study. The youngest patient was 12 years and the eldest was of 78 years old. The mean age was 39.73 years. There were 45 males and 50 females with a male to female ratio 1:1.1. The duration of white lesions in oral cavity ranged from 3 weeks to 10 years. Pain or burning sensation in the oral cavity was present in 52 (54.7\%) patients while $43(45.3 \%)$ did not have any symptoms. History of diabetes and hypertension were present in $6(6.3 \%)$ each and another $5(5.2 \%)$ had both diabetes and hypertension. Past history of cancer of buccal mucosa and tonsil were present in one each of them. Caries was detected in 32 (33.7\%) of patients and 12 (12.6\%) had amalgam filling. 33 patients (34.7\%) had habit of smoking and 27 patients $(28.4 \%)$ had habit of betel chewing and alcoholism.

$28(29.4 \%)$ had lesions involving bilateral buccal mucosa where as $26(27.4 \%)$ showed involvement of right buccal mucosa alone. Lacy pattern was the most common presentation in 47 patients (49.5\%) followed by uniformly white lesion (34.8\%). (Table 1).

Regional lymphadenopathy was present in 22 (23.1\%). $15(15.8 \%)$ had associated cutaneous lichen planus. Smear from $8(8.4 \%)$ patients showed positivity for candidal hyphae on $\mathrm{KOH}$ scraping and were given anticandidal treatment. Of these $50 \%$ had oral malignancy. All patients were nonreactive for VDRL and negative for HIV ELISA.

Clinical diagnosis in our study were oral lichen planus (61 patients; 64.2\%), leukoplakia $(29 ; 30.5 \%)$, discoid lupus erythematosus $(2 ; 2.1 \%)$ and oral submucous fibrosis (3;3.2\%).

A total of 95 patients, maximum number, 58 patients (61.1\%) had histologically oral lichen planus and 15 patients (15.7\%) showed dysplasia. Among 15, 12 cases were with mild dysplasia, 2 cases with moderate dysplasia and one with lichenoid dysplasia. 12 patients (12.6\%) had epithelial hyperplasia with chronic inflammation and 5 cases (5.2\%) had squamous cell carcinoma.

Clinic histological correlation (Table 2) was obtained in 93.4\% of lichen planus; only one showed lichenoid dysplasia, whereas among 29 leukoplakia 5 cases had SCC, one had verrucous carcinoma, 14 cases had dysplasia and 9 patients had epithelial hyperplasia. One out of three clinically diagnosed submucous fibrosis two showed histological correlation and one proved to have epithelial hyperplasia. There was no clinic histologic correlation for clinically diagnosed DLE which showed lichen planus and frictional keratosis respectively.

In finding out further statistical correlation only patients with histological diagnosis of lichen planus, dysplasia, epithelial hyperplasia and SCC (Total-90 patients) were included as other diseases like frictional keratosis, submucous fibrosis and verrucous carcinoma were less in number.

After cross tabulation with histopathologic diagnosis the mean age of patients was found to be higher in patients with SCC and dysplasia. (Table 3). All patients with SCC were males. Most of the patients with dysplasia, SCC and half with epithelial hyperplasia were asymptomatic which was found to be statistically significant. ( $p$ value: $<.001$ ). There was history of head and neck radiation in one case each of epithelial hyperplasia and SCC.

Risk factors including smoking, betel chewing and alcoholism were significantly higher among patients with epithelial hyperplasia, dysplasia and SCC (p: <.001). Pan masala use was present in 5.2\% lichen planus, $13.3 \%$ dysplasia, $16.6 \%$ epithelial hyperplasia and $60 \%$ of SCC. (Table 4).

Oral hygiene was poor in all patients with SCC. $(p:<.001)$. Statistically significant correlation was observed in occurrence of dysplasia over sites like lateral aspect and under surface of tongue, floor of mouth and palate.

Lacy pattern was more commonly seen in lichen planus group (74.1\%) and uniform white lesions in dysplasia (73.3\%). Three verrucous plaques turned out to be epithelial hyperplasia, verrucous carcinoma and SCC respectively. Three cases of white with red spots were histologically proved as one case of dysplasia and two cases of SCC. Ulceration was observed in $40 \%$ of SCC, induration in all cases of SCC and fibrotic bands in all cases of oral submucous fibrosis. ( $p$ value: <.001). Clinical pattern of SCC illustrated in Table 5, Figure 1c.

In dysplasia group, $86.7 \%$ had hyperkeratosis, patchy dermal infiltrate and mild dysplasia, $46.7 \%$ had parakeratosis, $66.7 \% \%$ had acanthosis and $13.3 \%$ had moderate dysplasia. In patients with SCC, all had hyperkeratosis, horn pearls and neoplasm infiltrating into dermis. (Figure 2).

\begin{tabular}{|c|c|}
\hline Characteristics & No. of Patients (\%) \\
\hline Lacy Pattern & $47(49.5)$ \\
\hline Uniformly White & $33(34.8)$ \\
\hline Lacy and Uniformly White Pattern & $5(5.3)$ \\
\hline Speckled Pattern & $3(3.2)$ \\
\hline Verrucous Pattern & $3(3.2)$ \\
\hline Erosion & $9(9.5)$ \\
\hline Ulceration & $3(3.2)$ \\
\hline Fibrotic Band & $2(2.1)$ \\
\hline Induration & $5(5.3)$ \\
\hline \multicolumn{2}{|c|}{ Table 1. Characteristics of white lesion } \\
\hline
\end{tabular}




\begin{tabular}{|c|c|c|c|c|c|c|c|}
\hline & $\begin{array}{c}\text { Lichen } \\
\text { Planus }\end{array}$ & Dysplasia & $\begin{array}{c}\text { Epithelial } \\
\text { Hyperplasia }\end{array}$ & SCC & $\begin{array}{c}\text { Verrucous } \\
\text { Carcinoma }\end{array}$ & $\begin{array}{c}\text { Frictional } \\
\text { Keratosis }\end{array}$ & $\begin{array}{c}\text { Oral } \\
\text { Submucous } \\
\text { Fibrosis }\end{array}$ \\
\hline Lichen Planus & 57 & 1 & 2 & 0 & 0 & 1 & 0 \\
\hline Leukoplakia & 0 & 14 & 9 & 5 & 1 & 0 & 0 \\
\hline Oral Submucous Fibrosis & 0 & 0 & 1 & 0 & 0 & 0 & 2 \\
\hline DLE & 1 & 0 & 0 & 0 & 0 & 1 & 0 \\
\hline Total & $\mathbf{5 8}$ & $\mathbf{1 5}$ & $\mathbf{1 2}$ & $\mathbf{5}$ & & & \\
\hline
\end{tabular}

\begin{tabular}{|c|c|c|}
\hline Histological Diagnosis & $\begin{array}{c}\text { Number } \\
\text { of Patients }\end{array}$ & $\begin{array}{c}\text { Mean Age } \\
\text { (in Years) }\end{array}$ \\
\hline Lichen planus & 58 & 47.17 \\
\hline Dysplasia & 15 & 52.75 \\
\hline Epithelial hyperplasia & 12 & 50.83 \\
\hline SCC & 5 & 61 \\
\hline Total & $\mathbf{9 0}$ & $\mathbf{5 2 . 9 4}$ \\
\hline \multicolumn{2}{|c|}{ Table 3. Age v/s Histological diagnosis } \\
\hline
\end{tabular}

\begin{tabular}{|c|c|c|c|c|c|c|}
\hline \multirow{3}{*}{ Habits } & \multicolumn{7}{|c|}{ Histopathological Diagnosis } \\
\cline { 2 - 7 } & & $\begin{array}{c}\text { Lichen } \\
\text { Planus }\end{array}$ & $\begin{array}{c}\text { Dys- } \\
\text { plasia }\end{array}$ & $\begin{array}{c}\text { Epithelial } \\
\text { Hyperplasia }\end{array}$ & SCC & P value \\
\hline \multirow{2}{*}{ Smoking } & Yes & 8 & 6 & 9 & 5 & \multirow{2}{*}{$<.001$} \\
\cline { 2 - 7 } & No & 50 & 9 & 3 & 0 & \\
\hline $\begin{array}{c}\text { Alco- } \\
\text { holism }\end{array}$ & Yes & 4 & 6 & 9 & 4 & \multirow{2}{*}{$<.001$} \\
\cline { 2 - 6 } $\begin{array}{c}\text { Betel } \\
\text { Chewing }\end{array}$ & Yes & 64 & 9 & 3 & 1 & \\
\cline { 2 - 6 } & No & 52 & 10 & 3 & 0 & \multirow{2}{*}{$<.001$} \\
\hline \multicolumn{7}{|c|}{ Table 4. Habits v/s Histological diagnosis } \\
\hline
\end{tabular}

\begin{tabular}{|c|c|c|c|c|c|}
\hline \multirow{2}{*}{ Characteristics } & \multicolumn{5}{|c|}{ Histopathological Diagnosis } \\
\cline { 2 - 6 } & $\begin{array}{c}\text { Lichen } \\
\text { Planus }\end{array}$ & $\begin{array}{c}\text { Dys- } \\
\text { plasia }\end{array}$ & $\begin{array}{c}\text { Epithelial } \\
\text { Hyperplasia }\end{array}$ & SCC & Total \\
\hline Lacy Pattern & 43 & 3 & 1 & 0 & 47 \\
\hline $\begin{array}{c}\text { Uniformly } \\
\text { White }\end{array}$ & 9 & 11 & 10 & 2 & 32 \\
\hline $\begin{array}{c}\text { Verrucous } \\
\text { Lesion }\end{array}$ & 0 & 0 & 1 & 1 & 2 \\
\hline $\begin{array}{c}\text { White with } \\
\text { Red Spots }\end{array}$ & 0 & 1 & 0 & 2 & 3 \\
\hline $\begin{array}{c}\text { Lacy and } \\
\text { Uniformly } \\
\text { White Pattern }\end{array}$ & 5 & 0 & 0 & 0 & 5 \\
\hline \multicolumn{7}{|c|}{ Table 5. Characteristics of lesion } \\
v/s histological diagnosis \\
\hline
\end{tabular}

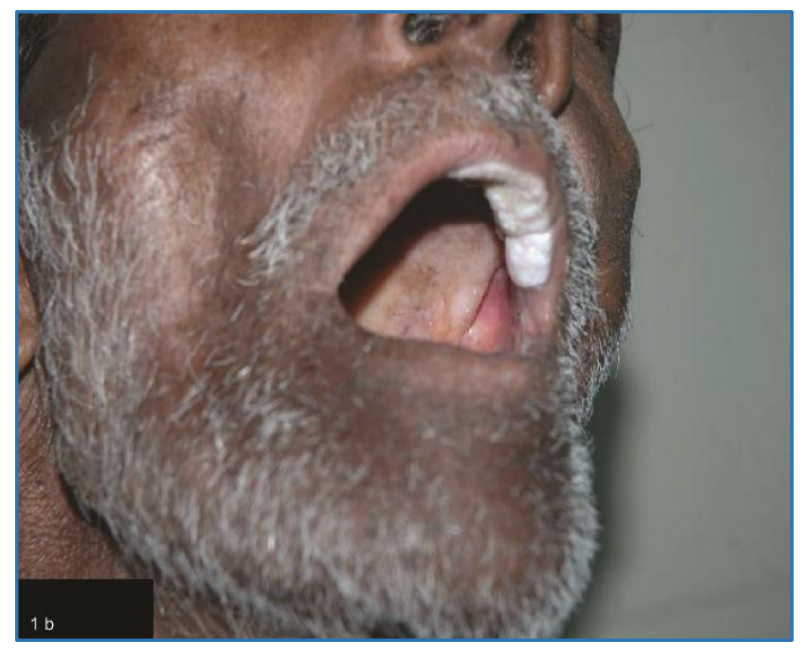

Figure 1b. Verrucous Leukoplakia

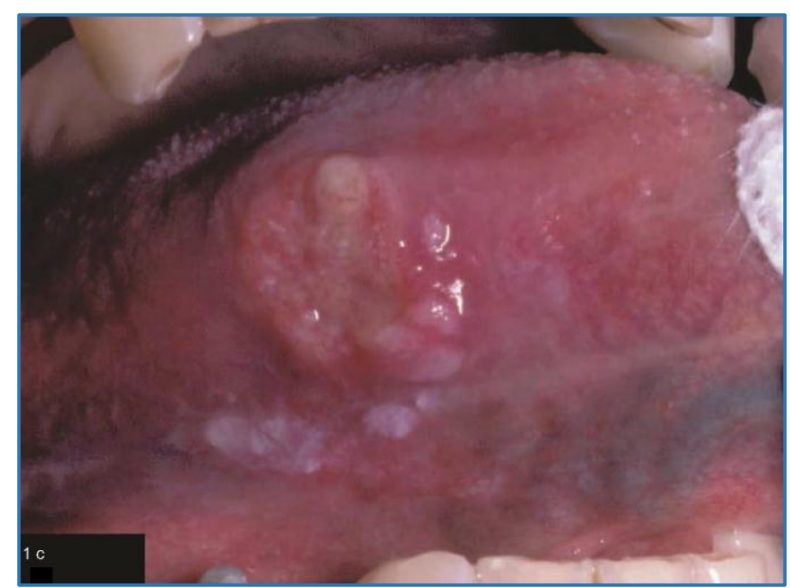

Figure 1c. SCC

Figure 2. Histopathology findings in (Haematoxylin and Eosin $\times 100$ )

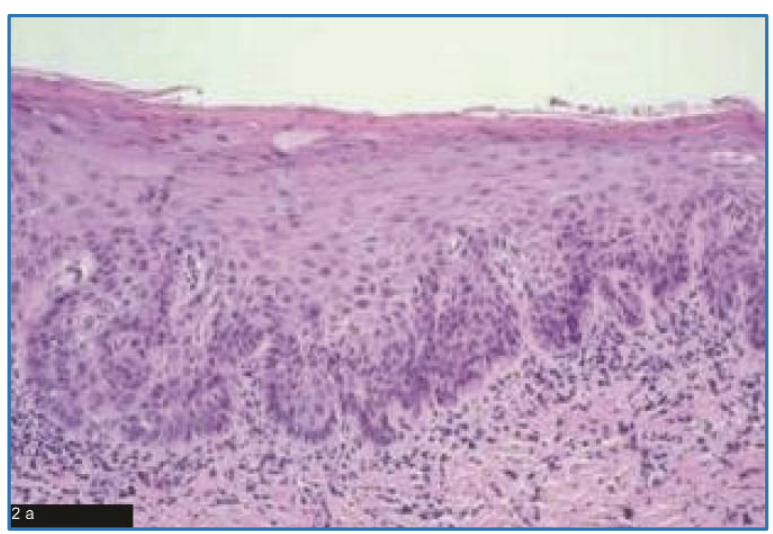

Figure 2a. Mild Epithelial Dysplasia 


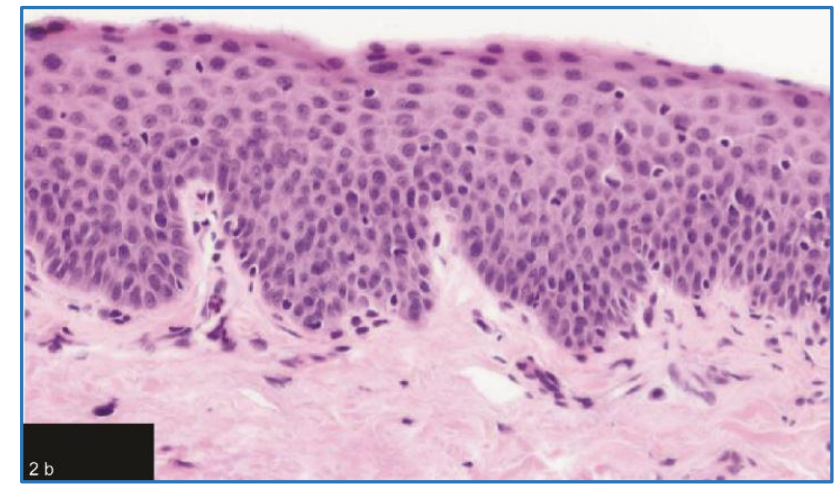

Figure 2b. Moderate Epithelial Dysplasia

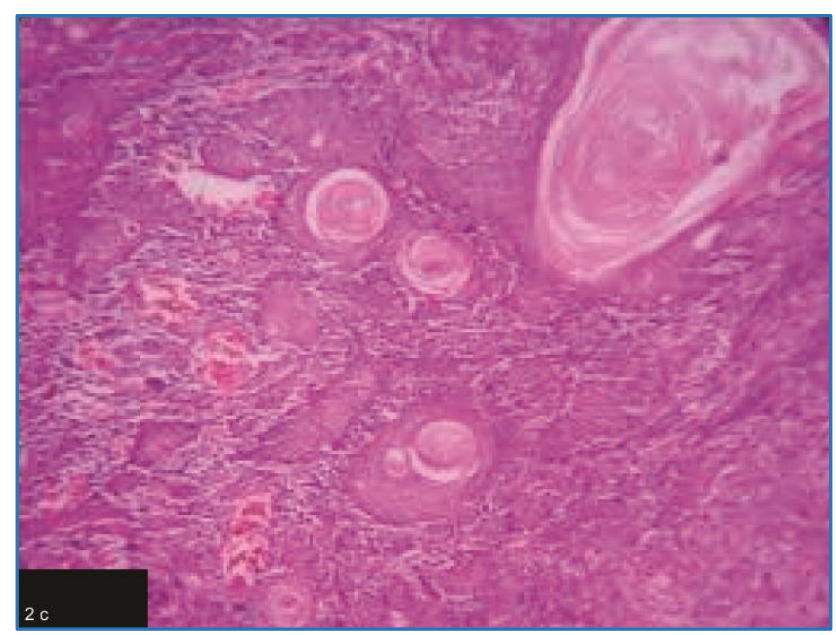

Figure 2c. SCC with Atypical Squamous Cells and Horn Pearls

\section{DISCUSSION}

White lesions in the oral cavity may be benign, pre-malignant or malignant. White appearing lesions of the oral mucosa obtain their characteristic appearance from the scattering of light through an altered mucosal surface which may be due to thickened layer of keratin, epithelial hyperplasia, and intracellular oedema or reduced vascularity. ${ }^{7}$

The principal method for assessing mucosal changes starts with recognition of risk factors. Clinical examination for oral premalignant lesions should include a thorough intra and extraoral examination including head and neck and cervical lymph nodes. A thorough oral mucosal examination should include recording of site, size, borders colour and surface characteristics of any lesion so that future changes can be appreciated. ${ }^{7}$

Some of these white lesions may be premalignant and their appropriate management depends upon early and accurate diagnosis. Oral premalignant lesions include leukoplakia, erythroplakia, dysplastic leukoplakia, dysplastic lichenoid lesion, oral submucous fibrosis, and lichen planus. Oral premalignant lesions have shown a rate of progression to malignancy of up to $17 \%$ within a mean period of 7 years after diagnosis. ${ }^{7}$ The frequency of dysplastic or malignant alterations in oral leukoplakia has ranged from 15.6 to $39.2 \%$ in several studies. ${ }^{8}$ In our study there were 6 cases $(20.6 \%)$ of malignancy among 29 leukoplakia cases. Far less common than leukoplakia, erythroplakia has a much greater probability (91\%) of showing signs of dysplasia or malignancy at the time of diagnosis. ${ }^{9}$
Chance for malignancy is up to $20 \%$ in oral submucous fibrosis. ${ }^{10}$ There was no dysplastic changes in submucous fibrosis in our study. There was one case of lichenoid dysplasia in lichen planus which should be kept under follow up due to risk of malignant transformation. ${ }^{11}$

Incidence of malignancy in our study was $6.3 \%$ which was comparable with other Indian studies (2-10\%),12 whereas less prevalence was (.005-.01\%) noted in western studies. ${ }^{13}$ This may be due increased pan masala usage and betel chewing in Indians.

Comparable with previous studies we also noticed increased incidence in elderly with a male predominance. Male predominance was due to mixed habits of alcoholism, betel chewing, pan masala usage and smoking. These factors produce additive effect leading to increase in tissue levels of carcinogens. Tobacco smoke containing nitrosamines is the source of the carcinogenic stimuli and alcohol facilitates the activation of tobacco-associated carcinogens. Nitrosamines are enzymatically converted to unstable electrophilic intermediates alkyl diazohydroxides which can react with nucleophilic centers in cellular macromolecules resulting in carcinogenicity. ${ }^{13}$ The enzymatic conversion of ethanol produced by the physiological oral microflora may lead to accumulation of increased levels of the carcinogenic intermediate acetaldehyde. The production of acetaldehyde from ethanol increases in smoking, heavy drinking and poor dental status. ${ }^{14}$ Betel quid is basically a flavoured and sweetened dry mixture of areca nut, catechu and slaked lime (Calcium oxide and calcium hydroxide) wrapped in a betel leaf (Piper betel) with tobacco (Gutkha) or without tobacco (Pan masala). Components of betel nut, primarily the alkaloid arecoline and polyphenols act as a carcinogens. These substances not only have general mutagenic, cytotoxic and genotoxic properties, but are also intricately involved in enzymatic, molecular and genetic mechanisms that result in the development of carcinogenesis. ${ }^{15}$ Betel quid (BQ) chewing produces reactive oxygen species that is detrimental to oral mucosa and can be directly involved in tumor initiation process, by inducing mutation, or by making the mucosa susceptible to environmental toxicants. ${ }^{16}$

Most common site of involvement of dysplasia and SCC were lateral aspect of tongue and floor of mouth. Moore and Catlin have shown that the floor of mouth and lingual vestibule, known as the 'drainage area of mouth', are high risk sites for dysplasia and further development of oral cancer. This is due to pooling of saliva and accumulation of carcinogens and also mucosa in this area is thinner and nonkeratinized, leading to accumulation of carcinogens.

Among 29 clinically diagnosed leukoplakia cases, verrucosity was noted in (3 patients; $10.3 \%$ ), specking (Mixed red and white lesions) in $(2 ; 6.8 \%)$ and rest $(23 ; 79.3 \%)$ were with homogenous white lesions. In our study incidence of malignancy was $100 \%$ in speckled leukoplakia, $66.7 \%$ in verrucous leukoplakia and $9.1 \%$ in homogenous leukoplakia. Atypical features like induration and ulceration are highly suggestive of malignancy. In our study induration was present in all cases of SCC and ulceration in $40 \%$ of them. Careful inspection of morphology of lesion is important as the chance for progression to malignancy varies; speckled >verrucous $>$ homogenous leukoplakia. ${ }^{17}$ 
Despite the great strides that have been made in improving the prognosis of a number of cancers throughout the world, the prognosis for oral cancer has not experienced a similar improvement. So it is highly advisable that oral biopsy be done ideally in all white lesions or at least in those with atypical clinical features.

\section{CONCLUSION}

The ability to control oral cancer will depend on two cornerstones: prevention and early diagnosis. Continuing educational campaigns are needed on the local, state, and national level in order to educate the public about the risk factors and early signs/symptoms associated with this disease. Individuals also need to be encouraged to seek regular professional oral examinations. Finally, healthcare workers must be encouraged to perform oral examinations as part of their routine field surveys and to be knowledgeable about early signs of oral carcinoma.

\section{REFERENCES}

[1] Scully C, Felix DH. Oral medicine-update for dental practitioner: oral white patches. $\mathrm{Br}$ Dent J 2005;199(9):565-72.

[2] Simi SM, Nandakumar G, Anish TS. White lesions in the oral cavity: a clinicopathological study from a tertiary care dermatology centre in Kerala, India. Indian J Dermatol 2013;58(4):269-74.

[3] Warnakulasuriya S, Johnson NW, van der Waal I. Nomenclature and classification of potentially malignant disorders of the oral mucosa. J Oral Pathol Med 2007;36(10):575-80.

[4] Jayant K. Statistical appraisal of the association of smoking and chewing habits to oral and pharyngeal cancers. Indian J Cancer 1977;14(4):293-9.

[5] Messadi DV, Waibel JS, Mirowski GW. White lesions of the oral cavity. Dermatol Clin 2003;21(1):63-78.

[6] Nair U, Bartsch H, Nair J. Alert for an epidemic of oral cancer due to use of the betel quid substitutes gutkha and pan masala: a review of agents and causative mechanisms. Mutagenesis 2004;19(4):251-62.
[7] Baig NJ, Ibrahim NW, Bukhari SGA, et al. Pattern and presentation of oral white lesions. Pak Oral Dental J 2012;32(1):26-30.

[8] Silverman S, Bhargava K, Smith LW, et al. Mailgnant transformation and natural history of oral leukoplakia in 57,518 industrial workers of Gujarat, India. Cancer 1976;38(4):1790-5.

[9] Shafer WG, Waldron CA. Erythroplakia of the oral cavity. Cancer 1975;36(3):1021-8.

[10] Aziz SR. Oral submucous fibrosis: an unusual disease. J N J Dent Assoc 1997;68(2):17-9.

[11] Fatahzadeh M, Rinaggio J, Chiodo T. Squamous cell carcinoma arising in an oral lichenoid lesion. JADA 2004;135(6):754-9.

[12] Sridharan S. Epidemiology, control and prevention of tobacco induced oral mucosal lesions in India. Ind J Cancer 2014;51(1):80-5.

[13] Hoffmann D, Hecht SS. Nicotine-derived JVnitrosamines and tobacco-related cancer: current status and future directions. Can Res 1985;45:935-44.

[14] Kocaelli H, Apaydin A, Aydil B, et al. Evaluation of potential salivary acetaldehyde production from ethanol in oral cancer patients and healthy subjects. Hippokratia 2014;18(3):269-74.

[15] Shiu MN, Chen THH, Chang SH, et al. Risk factors for leukoplakia and malignant transformation to oral carcinoma: a leukoplakia cohort in Taiwan. Br J Cancer 2000;82(11):1871-4.

[16] Javed F, Chotai M, Mehmood A. Oral mucosal disorders associated with habitual gutka usage: a review. Oral Surg Oral Med Oral Pathol Oral Radiol Endod 2010;109(6):857-64.

[17] Jain RK, Kumar M, Nath O. Oral leucoplakia. Indian J Dermatol Venereol Leprol 1995;61(6):339-41. 